\title{
RESEARCH OF THE POSSIBILITY OF DETERMINING THE EFFECTS OF EROSION IN DARK BROWN SOIL SLOPES OF THE SMALL CAUCASUS BASED ON SPATIAL ANALYSIS IN THE EXAMPLE GEDEBEY DISTRICT
}

\section{T.A. Hadjiyev}

Western Caspian University

\section{ABSTRACT}

In soil genetic factors, soil-absorbing factors have always been in the spotlight. The formation of genetic strata of the soil and the variation of time depending on various spatial factors remains a widespread and urgent topic in the classical soil science, which has been continuously monitored to date. It is well-known that the most favorable approach to the study of soils can be achieved by obtaining a comprehensive set of data by studying its interrelationship of the environment and natural complexes, studying its dependence on time and space.

Key words. soil diagnostics, soil type, carbonate, texture differentiation, natural complex, soil map. 


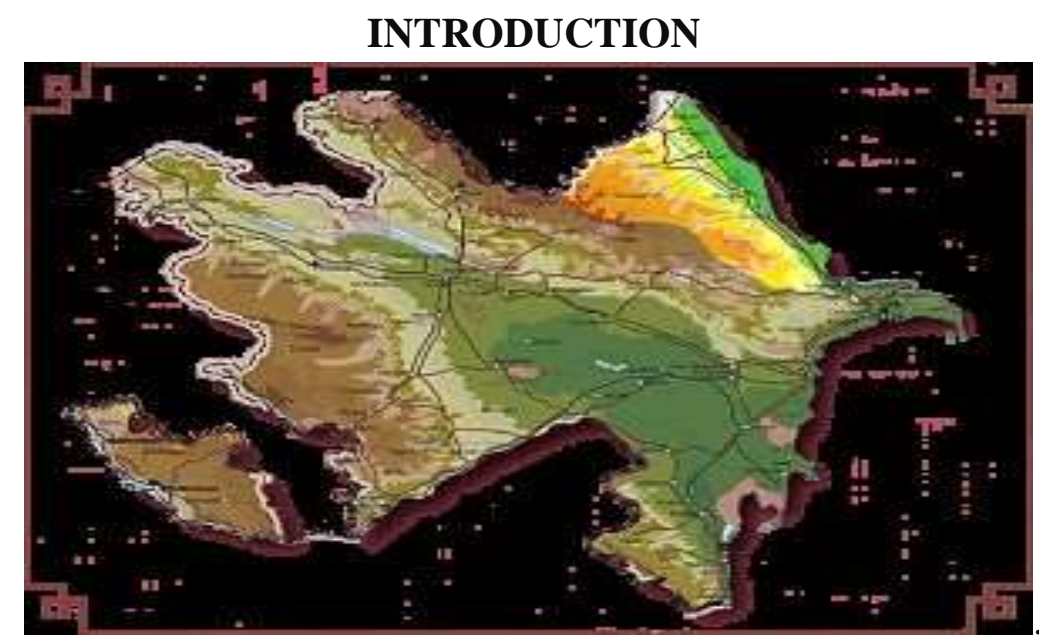

It is well known that the classification of brown soils was first made in 1949 by IP. Gerasimov. Although 69 years have passed since the first classification to date, brown soil has not yet been able to occupy its place in the classification. Thus, to substantiate the aforementioned idea, we have many years of theoretically and practically analyzed data.

It is known that brown soils are widely formed in the Balkan Peninsula and around the Mediterranean (European and African coasts).

This information was published in the works of the 6th International Congress of Soil Science, held in Paris in 1956.

The last classification of Azerbaijani lands was given by ME Salayev in 1991, where the author was especially interested in the search for correlation between the nomenclature system of the land and the system of nomenclature of the world with a more detailed study of the diagnostic parameters of soils.

Thus, when analyzing the results of SE Salayev's observations, attention is drawn to the specificity of mountain and brown soils from other types of soil and the relief and climatic complexity of the mountainous terrain.

As noted by Salayev ME, brown soils were formed on both flat and mountainous background.

However, it should be borne in mind that the brown soils in Azerbaijan have largely formed their genetic characteristics in the complex exposition of the mountainous relief and retained their classic morphological features.

You don't have to go very far to justify this idea. Thus, it is possible to encounter mountainous brown and mountainous lands in the northeastern part of the Lesser Caucasus, with a large range of Gadabay.

Brown soils are associated with the gray-brown soils formed in the foothills and forests of the Gadabay region from the south. In the upper border, brown mountain-forest lands create a transition to dark brown soils. The brown area of the forest zone has developed from 400-500m up to $1100-1200 \mathrm{~m}$, mainly under oak and partly forest. 
The brown soils present in flat areas have been able to change their geographical range because of their long-term anthropogenic impact.

Thus, the brown soils formerly formed under the forest now retain their original position in a very small range, while the rest are undergoing evolution.

\section{Research object and methodology.}

As a research object, the brown and black soils formed on different slopes of the northern slope of the Lesser Caucasus were taken. The degree of soil erosion at the study site was determined based on the comparative geographical method proposed by Alakbarov KA, and the determination of morphogenetic features by Sh.G. Hasanov.

\section{Analysis of results.}

Multispectral space images of Landsat-2 (1976) and Landsat-8 (2016) were used at different times to study the variability of the soil range in the study area.

Based on the processing of these images, an electronic map was developed to determine the time dependence of the shape of the terrain on the changes in the terrain, its effects on the types of soil formed in the area, and their morphological features.

Both electronic maps were developed based on ArcGIS version 10.3 $[3,4,11]$.

As you can see from the electronic map, over the 40 years from 1976 to 2016 , the land cover has changed significantly (photo 1,2).

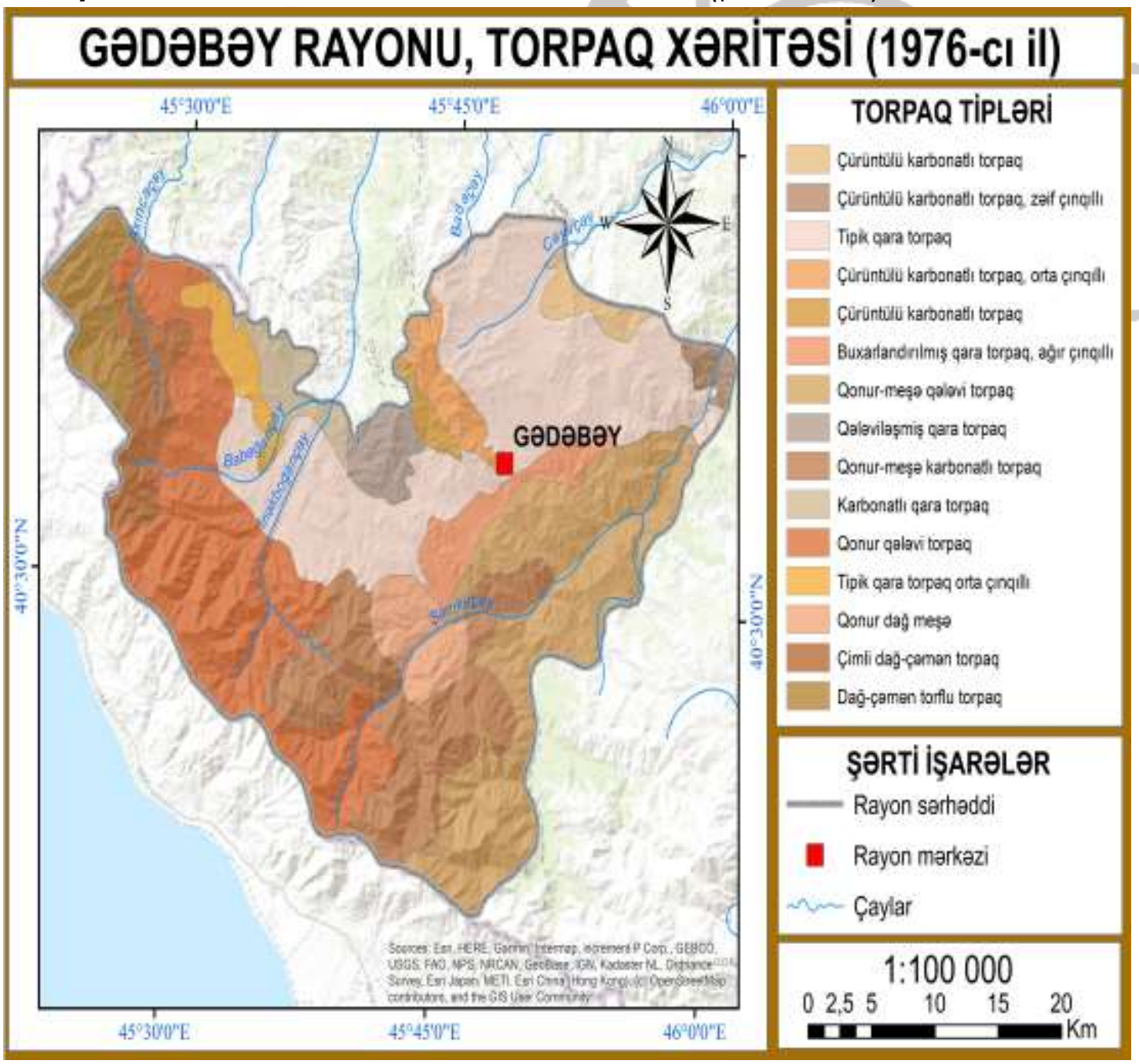


Figure 1. Land map of Gadabay region (1976)

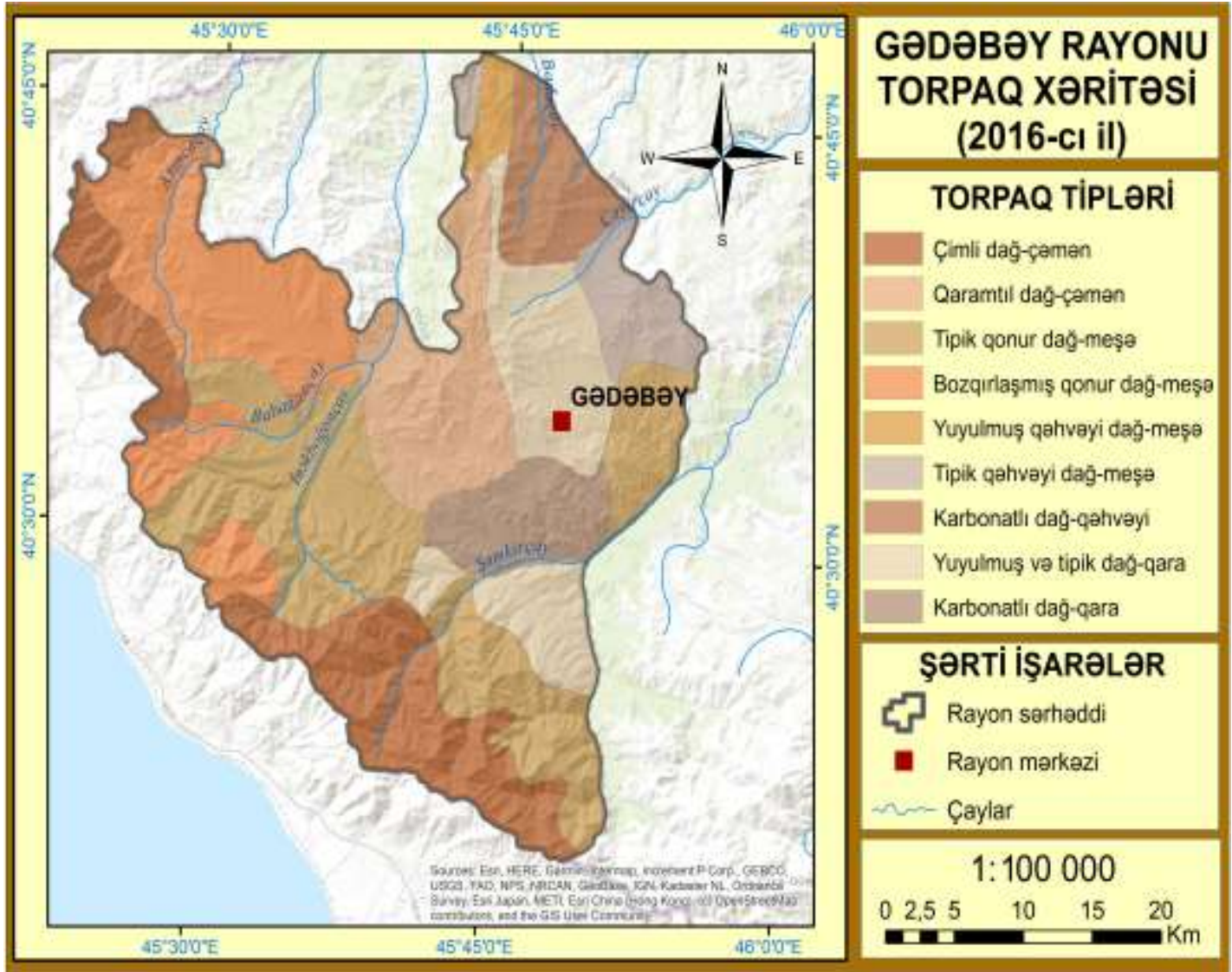

Figure 2. Land map of Gadabay district (2016)

Now The areas exposed to anthropogenic impact are shown on the map in a dense background. Visual observations at the landfill were analyzed and compared with Landsat-2 and Landsat-8 satellite images.

All of this suggests that, as a result of various natural and anthropogenic factors, the terrain changes and changes the nomenclature sequence according to the relevant taxation system. V.R. Volobuyev still regarded biogeochemical processes as the most complex indoor system in nature in his research and thesis in the middle of the last century $[1,2,5]$.

According to him, the main element of the process of degradation in nature, especially in soil, should be vegetation, which is clearly dependent on the eco- geomorphology of the surrounding area. $[1,9,12]$

Of course, one of the main factors that create continuity and recurrence in the aforementioned processes should be the atmospheric sediment and groundwater. The irritating and decisive nature of groundwater in the soil plays a key role in the formation and development of many processes.

It has a powerful effect on the formation of secondary mineral compounds, especially in soils, and in parallel with the vegetation removal from the soil profile.

It is not wrong to say that all these features are important in the management of landslide processes that may occur within a local or global space, depending on time. One of the main 
diagnostic features of brown mountainforest soils is the high carbon dioxide or uniform distribution throughout the profile, which is observed differently in the submerged or submerged subspecies.

Given that the activity of the thermal regime in the northern slopes is a major factor affecting the timing of vegetation season, we can say that the process of landing is clearly under different quality indices.

Further, it is worth noting that active temperatures have a superior role not only on the surface of the soil, but also on the inland soil. One of the main diagnostic indicators that draws our attention is the rate of intensive growth of the clay layer, which is formed by inland soil degradation in the brown carbonate and submerged soils. $[3,7,11]$

Observations and studies show that one of the main factors influencing the formation of brown forest lands is the relatively dry climate. Under these conditions, thick mesophylous forests do not form, but only drought-resistant and relatively low-prone forest species can produce species and xerophytes.

All these processes are associated with the high evaporation rate and the less intense precipitation.

In general, when analyzing the results of studies conducted by both local and foreign scientists, we can see that the nature and direction of the soil processes, as well as the evolutionary direction, are directly influenced by the factors affecting the soil. The more effective the mechanism of soil-borne factors is, the more time-dependent it becomes in directing the process $[1,6,14]$.

Result. From the analysis and discussion of the analytical information presented in the article, we can conclude that the collapse of the brown and black soils and the deforestation of trees and shrubs in the low-mountainous zone is not only a consequence of local ecosystem changes but also the fertility of the soil.

Changes in the genetic make-up of the soil have led to the different taxonomy of the relatively high taxon, which does not deviate from its typical diagnostic and morphological characteristics. As a result, the area of the fertile layer of both types of land has been significantly reduced.

\section{Literature.}

1. Aliev BH, Aliev IN, Aliev ZH District of Azerbaijan in progressive technical policing. Baku: Zia-NPC Nurlan, 2009, 290 $\mathrm{P}$

2. Aliev ZH Modern Protective Areas of occupied Territory in Azerbaijan. Geological and Mineralogical Sciences, No. 4. SNT, 2014, pp. 8-15

3. Aliev $\mathrm{ZH}$ Methods used in the definition of stomping dislocations in the post-erosion erosion. 2015: Agriculture year in the Azerbaijan Republic. Baku. 15 December 2015, pp. 56-57

4.Babayev MP, Jafarova Ch.M. and others. Applied genetics-classification of postage Azerbaijan // Post- Consolidation - Production and Ecological Safety, VII Congress Общества поставоведов им. VV Dokuchaeva, Publications Article 1. Moscow, Belgorod, 2016, pp. 54-55

5.Brevik E.C. The potential impacts of climate change on soil properties and processes and the relevant impact on food security // Agriculture, 2013, vol.3, pp. 398-417 
6.Kerullayev AS, Shamilzade TM, Ismailova MZ Soil-erosion $\mathrm{p}$ Ways of solving the problem of rheumatism, Actual problems of ecology and soil science in the 21 st century, III Republican Scientific Conference, Baku, May 7-8, 2014, Baku University Publishing, pp. 457441.

7.Knizhnikov JF, Kravtsova VI Aerospace Dynamic Geographical Juggling. Search Moscow State University, 1991: $205 \mathrm{p}$.

8. Kronberg P. Remote Reading Moscow: Mir, 1988, pp.107-128.

9. $\vee \vee$ Volobuev "Ecology of mail", Academy of Sciences of Nauk Azerbaijan, Baku 1963, pp.20-21.

10. Nearing M.A., Pruski F.F. etc. Expected climate change impacts on soil erosion rates: A review // Journal of Soil and Water Conservation, 2004, vol.59, No.1, pp. 43-50

11.E.E. Salayev «Diagnostics and Classification of Azerbaijan Republic», "Elm", Baku 1991, pp. 138-141

12. Salayev EE "The Cornish Papers" Genetic postage subtropics of the Transcaucasia, Moscow "Nauka", Moscow 1979, pp 126-127.

13. Rhode AA "Genesis of postmodern and post-modern processes", "Science", Moscow .1984, pp.85-90.

14. Tubalov AA Analysis and analysis of post-erosion processes on basic applications of computer technology mapping. West. Volgogr. gos. flour Ser 3, Econ. Ecol. 2011 . No. 2, p. 253-259. 